\title{
Source term model of radioactive liquid spills for actual decision support systems
}

\author{
Yurii Kyrylenko ${ }^{1,2,3,}$, Iryna Kameneva ${ }^{3}$, Oleksandr Popov $^{2,3,4}$, Andrii Iatsyshyn $^{2,3}$, Iryna Matvieieva ${ }^{5}$, Valery Bliznyuk ${ }^{6}$, \\ and Norbert Molitor ${ }^{7}$ \\ ${ }^{1}$ State Scientific and Technical Center for Nuclear and Radiation Safety, 35-37 V. Stusa Str., Kyiv, 03142, Ukraine \\ ${ }^{2}$ State Institution "The Institute of Environmental Geochemistry of National Academy of Sciences of Ukraine", \\ Department of environmental protection technologies and radiation safety, 34a Palladin Ave., Kyiv, 03142, Ukraine \\ ${ }^{3}$ G.E. Pukhov Institute for Modelling in Energy Engineering of NAS of Ukraine, Department of Mathematical and Econometric \\ Modeling, 15 General Naumova Str., Kyiv, 03164, Ukraine \\ ${ }^{4}$ Interregional Academy of Personnel Management, 2 Frometivska Str., Kyiv, 03039, Ukraine \\ ${ }^{5}$ National Aviation University, Faculty of Environmental Safety, Engineering and Technology, 1 Liubomyra Huzara Ave., \\ Kyiv, 03058, Ukraine \\ ${ }^{6}$ Clemson University, Department of Environmental Engineering and Earth Sciences, 342 Computer Court, Anderson, SC 29625, \\ United States of America \\ ${ }^{7}$ PLEJADES GmbH - Independent Experts, Feldstr. 5 D-64347, Griesheim, Germany
}

\begin{abstract}
Spills of liquid radioactive material are reviewed as potential event that can be associated with release into the atmosphere. Existing approaches to radiological impact assessment for onsite as well as offsite of facility are presented. The example of using the actual Java version of the European RODOS system as prototype of the decision support system shows the general implementation of the analysis and preparation of initial data in order to model the radiological impact on the public, personnel and environment. Given the specifics of the occurrence of emergency scenarios of this type, features of atmospheric models application, description of the source term model, software integration features, ventilation task solving, completeness and format of the initial data required for radiological consequence modelling.
\end{abstract}

\section{Introduction}

Today, more and more often in order to model the radiological impact on the public, personnel and environment, decision support systems (DSS) for responding to nuclear and radiological accidents in real time are used (RODOS, ARGOS, HPAC, NARAC, etc. [1-6]). In addition to the primary tasks of the software, they are also applied in frame of emergency preparedness and planning, quantitative and qualitative analysis of possible scenarios taking into account the evolution and phenomenological stages of the events. This is primarily due to the wide range of data assessment tools both in terms of design capacity and in terms of simplicity of input and analysis of results. However, at present, a significant challenge for users of these DSS is to prepare a correct and complete package of initial data, in particular, source term data for each of the emergency scenarios under consideration. A large number of works are devoted to the development of separate special tools for creating information communication between source term assessment codes and radiological impact assessment systems. For instance developers of RASCAL have been overcome the obstacle related to fast source term assessments and simplified atmospheric modelling calculation that is fully justified by emergency response goals. However, the wide variety of potential emergency processes at nuclear power plants does not allow to create unified tool for preparing source term data that would cover all possible state of the affected facility.

An important area of nuclear power plant (NPP) safety analysis is the analysis of emergency scenarios associated with the spill of radioactive liquids [2]. In this paper, on the example of the use of JRODOS DSS, the basic requirements for the initial data in order to model the radiological impact in accidents are formed.

Worldwide there have been more than 30 significant accidents with spills of liquid radioactive materials at nuclear fuel cycle facilities for the last 60 years according to work [3]. Among there is the accident at research reactors, nuclear power plants, nuclear complexes, uranium facilities, pilot plants and chemical plants, etc.

Many special computer codes and methods are currently developed to assess, with sufficient accuracy, parameters of releases for various accidents at nuclear fuel cycle facilities (e.g. MELCOR computer code manual, US NRC for NPP). But, according to study [2, 3], these codes have some disadvantages and often require a large amount of input data, calculation time.

\footnotetext{
* Corresponding author: uo kyrylenko@sstc.ua
} 


\section{Analysis of previous publications}

In the world practice of liquid radioactive material (LRM) - related events analysis assessments of the radionuclides distribution in the liquid-vapor system are based on the results of research (model and experimental data) in the context of normal operation, summarized in the standards and guidelines and standards of the US NRC such as NUREG-0016 [4], NUREG-0017 [5] on calculation of releases of radioactive materials in gaseous and liquid effluents. American National Standards ANSI/ANS-18.11999 [6] ANSI/ANS-18.1-2016 [7] have information on radioactive source term for normal operation of light water reactors. Among the latest studies in the direction of investigation on the intensity of evaporation from open surfaces of liquids [8-11] can be considered. Detailed description of the models integrated in actual decision support system JRODOS can be found in [12-14]. Studies on thermodynamic calculations ventilation and air conditioning, experimental data of heat and mass transfer during evaporation of the liquid with a free surface, thermodynamic properties of water and steam are collected in [5-20]. Information on existing toolkit for ventilation task solving, atmospheric dispersion modelling and dose projection such as ANSYS, Solid Works, OpenFOAM, MACCS, RASCAL, HOTSPOT is concentrated in [21-28]. The report [31] is focused on the results of the AVESOME project on source term uncertainties in decision support system context.

The publications [32-37] provide an information on existing procedures and format for data exchanging covering USIE platform, decision support systems and adjacent software.

The aim of the work is to complete the all stages of radiological consequences analysis for the group of events related to radioactive material spills using developed source term model taking into account requirement from side of actual decision support systems. It can be achieved due to solving of the next tasks:

- to give the definition of LRMs and describe the area of their application;

- to present proposed source term model;

- to put the light on integration of the developed model in context of actual approaches to ventilation task solving, atmospheric dispersion modelling and dose projection;

- to overview the uncertainties associated with source term modelling taking into account nowadays decision support systems and international projects conducting;

- to provide recommendation in selection of suitable atmospheric dispersion model on example of JRODOS system;

- to describe actual exchanging data format to approach the link between the stages of modelling.

\section{The research results}

\subsection{Radioactive liquids}

LRM are liquid solutions, which include impurities of radioactive elements (possibly bound in high-molecular complexes). The isotopic composition of LRM is determined primarily by the source of radioactive impurities. The main sources of LRM at nuclear power plants and nuclear complexes are as follows:

- primary coolant that is discharged for operational reasons;

- water that is used to back flush filters and ion exchangers;

- floor drains that collect water that has leaked from the active liquid systems and fluids from the decontamination of the plant and fuel flasks;

- leaks of secondary coolant;

- laundries and changing room showers;

- and chemistry laboratories.

LRM can be located: both under containment of NPP units and beyond (for example, in an auxiliary building). At Ukrainian power units, temperatures of the LRM can reach $320^{\circ} \mathrm{C}$ (under pressure), fluctuations in the range from 40 to $100^{\circ} \mathrm{C}$ are possible in pipelines and tanks, depending on the ways of discharge of radioactive effluents. Accidents involving LRM spills are characterized by intense heat transfer due to the evaporation of the liquid - the formation of vapor-aerosol forms, which are subsequently localized on the materials of treatment or localization systems - for example, on drops of a sprinkler system or on gas-aerosol filters of ventilation equipment. In case of disability of localizing systems, significant emissions of radionuclides can be considered due to the leakage from the emergency rooms.

The isotopic composition and activity of the LRM at the NPP varies greatly. E.g., the primary coolant and the water of NPP spent fuel pool holding with light water reactors makes a collection of fragments of forced separation ${ }^{235} \mathrm{U}$ and ${ }^{238} \mathrm{U}$, isotopes of corrosion metals, neutron activation products, etc. Within an auxiliary building, radioactive media can be maintained for a long time and include only long-lived radionuclides $\left({ }^{60} \mathrm{Co}\right.$, ${ }^{134} \mathrm{Cs},{ }^{137} \mathrm{Cs},{ }^{54} \mathrm{Mn}$ etc.) in the isotope composition. A similar case is observed in research reactors. Heavy water, which is used as a moderator on liquid reactors, also has high activity due to the presence of tritium in it.

World nuclear complexes produce and process radioactive materials (e.g. NPP fuel, isotopic mixtures, industrial and medical sources). At nuclear complexes, as well as at nuclear power plants, reactor installations of different capacity are used. Nuclear complexes, chemical plants and research centers also work with the LRM. A distinctive feature of these enterprises in comparison with the NPP, in terms of the characteristics of the LRM used, is the large range of radioactive solutions involved in the technological processes of the enterprise.

At nuclear power plants and nuclear complexes, LRM are mainly aqueous solutions of decay products of nuclear fuel according to International Atomic Energy Agency (IAEA) safety standards and FSUE's materials [7]. Pilot plants and chemical plants may contain a full range of isotopes and solvents. LRM can be found on the site for processing the radioactive liquids.

Issue is a significant problem for radiotherapy medical hospitals. The problem is to analyze the emergency situations related to the special reservoir systems in the underground rooms of hospital (DTS systems - Decay Tank Systems containing ${ }^{99 \mathrm{~m}} \mathrm{Tc},{ }^{131} \mathrm{I},{ }^{18} \mathrm{~F}$, shown in Fig. 1). 


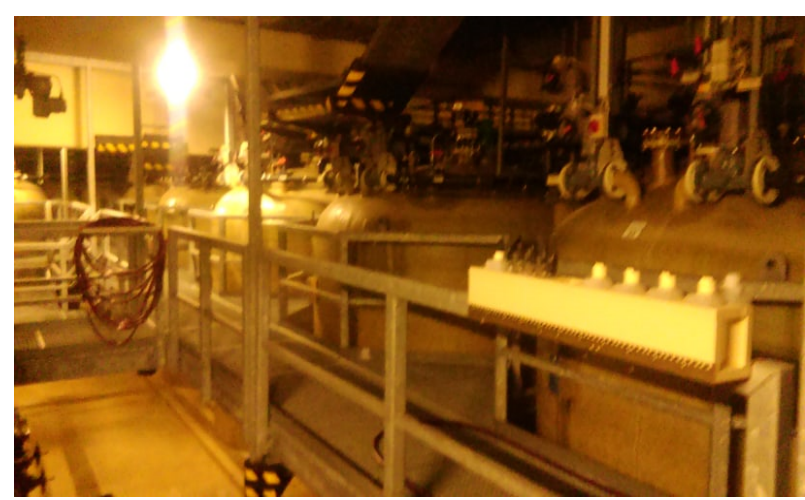

Fig. 1. DTS (Decay Tank Systems).

\subsection{Source term model}

The proposed approach is based on the theory of nonstationary heat and mass transfer in surface evaporation of liquid heated below the boiling temperature.

The physical model includes: active liquid medium, steam-aerosol radioactive mixture (SARM), air of forced ventilation, airborne filters, and the floor of emergency area. The key aspects of the model are evaporation of liquid material, its removal with exhaust ventilation and partial trapping on airborne filters. It is considered that SARM is released to the environment after filters.

The model is developed to assess the radiation consequences in an accident with spill of LRM and describes the spread of radioactive material by two consecutive ways: releases within the emergency area and further transfer of SARM into the atmosphere. In this paper, we focus on the relationship of these pathways and study the process of evaporation as special one for accident with spill of LRM (Fig. 2).

To solve the problem of unsteady LRM evaporation, four balance differential equations were written to relate the main parameters of LRM and air space of area over time.

$$
\left\{\begin{array}{l}
\frac{d m_{w}}{d t}=-\beta_{s w}\left(p_{s w}-p_{m}\right) S-G_{d} \\
\frac{d m_{a}}{d t}=\beta_{s w}\left(p_{s w}-p_{m}\right) S-G_{V} \cdot \frac{m_{a}}{V} \\
\frac{d m_{q}}{d t}=G_{V} \frac{m_{a}}{V}(1-\psi) \\
\frac{d T_{w}}{d t}=-\frac{r_{w} \beta_{s w}\left(p_{s w}-p_{m}\right) S+k F\left(T_{w}-T_{f}\right)}{c_{p} m_{w}}
\end{array}\right.
$$

where $m_{a}$ - current mass of SARM in air of the area, $\mathrm{kg}$;

$G_{d}$ - flowrate of LRM through the drainage channel (it also includes the volume of LRM leakage from the area), $\mathrm{kg} / \mathrm{s}$

$V$-air volume in the area, $\mathrm{m}^{3}$;

$G_{V}$ - flowrate of involved air of forced ventilation (this parameter includes SARM leakage through the gaps or clearances in walls of the emergency area) $\mathrm{m}^{3} / \mathrm{s}$;

$\psi$ - coefficient of filtration (efficiency of filtration);

$m_{q}$-mass of released SARM into the atmosphere, $\mathrm{kg}$.

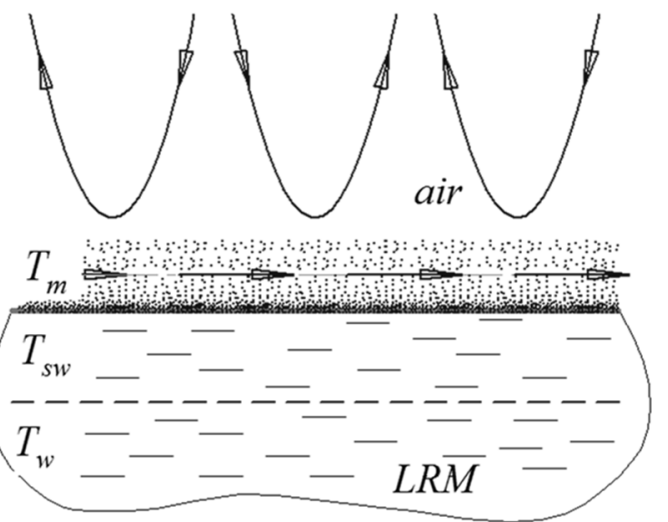

Fig. 2. The temperature layers near the surface of LRM.

Functions $\beta_{s w}\left(T_{s w}\right), p_{s w}\left(T_{s w}\right), p_{m}\left(T_{m}\right), r_{w}\left(T_{w}\right)$ and $c_{p}\left(T_{w}\right)$ are polynomials. They are compiled according to [8-12].

In model, the performance of forced ventilation unit is determined by the flowrate of involved air. After the exhaust ventilation pipe, SARM partially settles on filters. This phenomenon accounts for the coefficient of filtration. It determines the relative amount of SARM that is deposited on the filter material. SARM further passes through the ventilation stack into the atmosphere.

Another method to confine LRM is to drain the spilled liquid by drainage pumps or by gravity. This process is characterized by the flowrate of LRM through the drainage channel.

The partial removal of radioactive substances from the liquid by evaporation depends on physicochemical properties of radioactive impurities and the solvent.

This system of nonlinear differential equations includes polynomial functions. Using the Mathcad sphere for solving the system of equations provides the desired functions in matrix form (the values of the functions at particular moments of accident).

Average activity concentration of the radionuclide in the area air $A_{\text {air }}\left(B q / \mathrm{m}^{3}\right)$ is given by the formula

$$
A_{\text {air }}=\frac{A_{w}}{V} H \cdot m_{a}
$$

The ultimate objective of the model is to determine the dynamics of LRM evaporation, SARM activity in the air space and the integral release of radioactive substances into the atmosphere. The mass fraction of a radionuclide in the release relative to its original content in radioactive liquid is commonly used in practice:

$$
q=\frac{A_{w}}{m_{0}} H \cdot m_{q} \cdot 100 \%
$$

where $m_{0}$-initial mass of LRM, $\mathrm{kg}$

This value is used as an input parameter for the assessment of doses to the public from atmospheric release.

\subsection{Ventilation task solving}

Using such products as ANSYS software [13], OpenFOAM [14], SolidWorks [15] additionally studies the impact of forced ventilation system on the velocity of the underlying layer supply air. The velocity values found 
are used to clarify the surface temperature of the liquid according to [8-12]. The results of the impact analysis revealed that the speed the incoming flow has a significant effect on the evaporation intensity, as the consequence on the ejection. Therefore, one of the prerequisites for the preparation of initial data and boundary conditions for the model is a preliminary ventilation solution tasks within the established technological parameters.

Using the SolidWorks software, the influence of the ventilation system flow on the velocity of the underlying inlet air layer was investigated (Fig. 3-5).

\subsection{Integration in atmospheric dispersion and dose projection tools}

Based on the results of the mathematical model with a view to further determination of radiological impact on the workers, public and the environment the environment can be used analytical methods and software tools (Table 1).

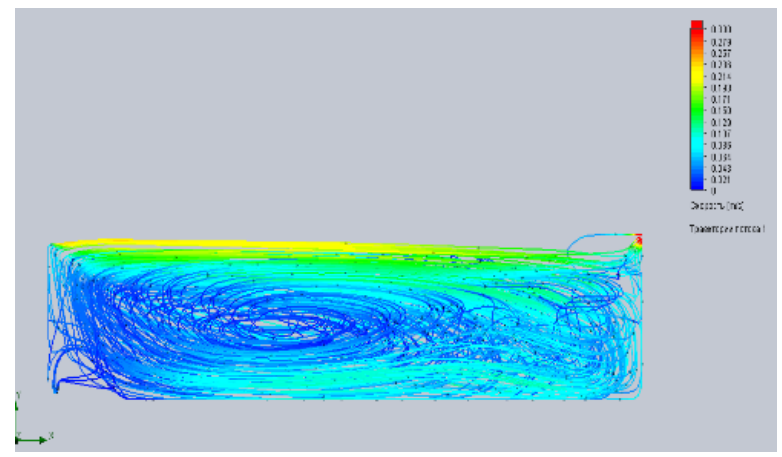

a)

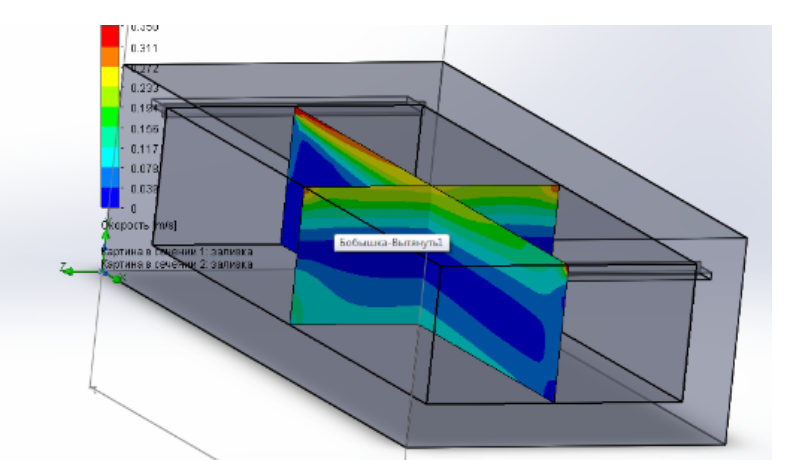

b)

Fig. 3. Air flow fields SolidWorks simulation $\left(G_{V}=0,75 \mathrm{~m}^{3} / \mathrm{s}\right)$ : flow trajectories (a), velocity fields (b).

Real-time On-line Decision Support System for offsite emergency management (RODOS) provides consistent and comprehensive information on radiological situation development, the extent and the benefits and drawbacks of emergency actions and countermeasures, and methodological support for taking decisions on emergency response strategies. Main users of the system are those responsible at local, regional, national and international levels for off-site emergency management.
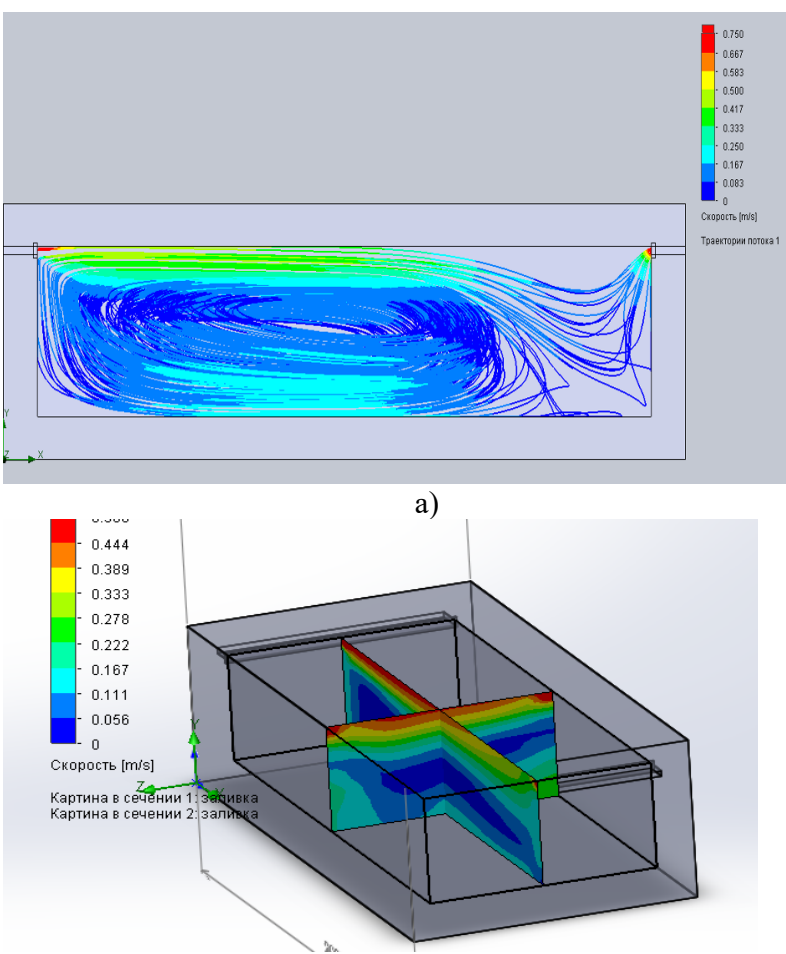

b)

Fig. 4. Air flow fields SolidWorks simulation $\left(G_{V}=1,5 \mathrm{~m}^{3} / \mathrm{s}\right)$ : flow trajectories (a), velocity fields (b).

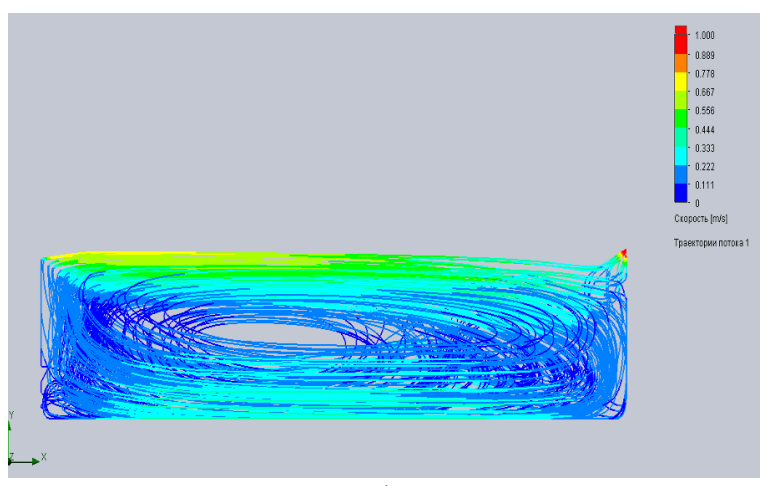

a)

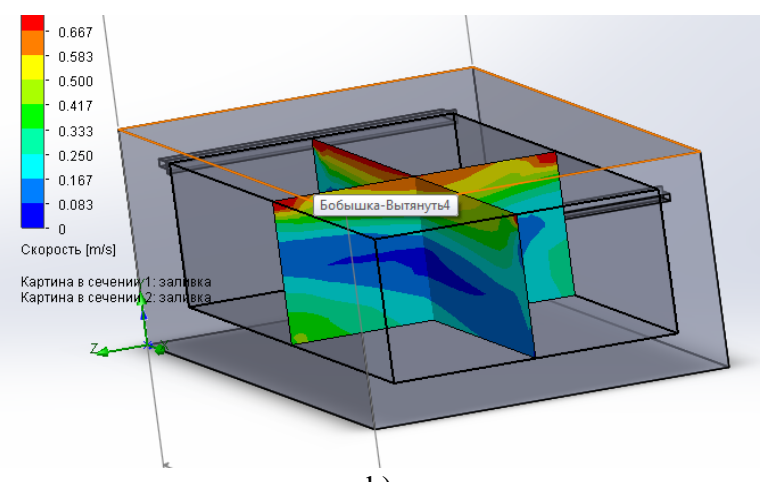

b)

Fig. 5. Air flow fields SolidWorks simulation $\left(G_{V}=1,5 \mathrm{~m}^{3} / \mathrm{s}\right)$ : flow trajectories (a), velocity fields (b).

RODOS has the most diverse collection of dispersion models, with one of each type of dispersion model incorporated into the code: Lagrangian (RIMPUFF, DIPCOT and LASAT), Eulerian (MATCH). Additional decision aiding components can facilitate the ranking and selection of alternative options using decision analysis 
procedures. Thus, RODOS system allows real-time operation for offsite emergency management as well as applications for exercise, preparedness, and planning.

Table 1. Font styles for a reference.

\begin{tabular}{|c|c|c|}
\hline \multirow{2}{*}{ Model outputs } & \multicolumn{2}{|c|}{ Workers exposure } \\
\hline & internal & external \\
\hline \multirow[t]{2}{*}{$\begin{array}{c}\text { Array of air } \\
\text { concentrations in } \\
\text { emergency room } \\
\operatorname{Av}(\mathrm{t})\end{array}$} & $\begin{array}{c}\text { Analytical base } \\
\text { and methods } \\
\text { (NRC, ICRP, } \\
\text { UNSCEAR } \\
[16]) ; \\
\text { • Dose } \\
\text { conversion } \\
\text { factors FGR- } \\
11 / 13, \text { EPA [16] }\end{array}$ & $\begin{array}{c}\text { - Analytic base (NRC, } \\
\text { EPA, ICRP) }+ \text { dose } \\
\text { from skin exposure }(\alpha \\
\text { and } \beta) ; \\
\text { - MICROSHIELD, } \\
\text { ISOCSR (+ dose from } \\
\text { equipment and spill } \\
\text { domain) [16] }\end{array}$ \\
\hline & \multicolumn{2}{|c|}{$\begin{array}{c}\text { Public exposure and environmental } \\
\text { contamination }\end{array}$} \\
\hline $\begin{array}{l}\text { Array of time- } \\
\text { integrated activity } \\
\text { released into the } \\
\text { atmosphere } \\
\text { (source term) } \\
\mathrm{Q}(\mathrm{t})\end{array}$ & \multicolumn{2}{|c|}{$\begin{array}{c}\text { • RODOS: RIMPUFF atmospheric } \\
\text { dispersion model with 10-min. time } \\
\text { step + FDMT [17]; } \\
\text { - ARGOS: complex terrain ADM, dose } \\
\text { projection module (any other DSS); } \\
\text { sophisticated models for short range } \\
\text { (CFD-, LES-modeling); } \\
\text { - simplified Gaussian models HOTSPOT } \\
\text { [18], RASCAL (INTERRAS) [19]; } \\
\text { NRC MACCS code (probabilistic } \\
\text { analysis tool) [20]; } \\
\text { - GENII, RESRAD, PAVAN, ARCON } \\
\text { 96, XOQDOQ (RAMP codes family) }\end{array}$} \\
\hline
\end{tabular}

RODOS is user-friendly and has an intuitive graphical user interface. The integration of GIS functionalities enables graphical representation of results. JRODOS features and tools allow the adaptation of the system to national conditions and user preferences.

In 2013 in the frame of European Commission project INSC U3.02/08 (UK/RA/08) Java-based Decision Support System JRODOS was installed in SNRIU's Information and Emergency Centre (IEC). At the Rivne NPP, the RODOS system was implemented in 2012. The RODOS system was installed at the central post of the automated radiation monitoring system (ASRM). ASRM equipped with powerful meteorological complexes that is very important for the use of RODOS. Data in special formats from four ASRM meteorological complexes, from radiation monitoring points and mobile laboratories are transmitted to RODOS via software that ensure interface of ASRM with RODOS. On October 8-10, 2013, the training course "Program system JRODOS - new multiplatform version of the European DSS for the offsite nuclear emergency management - RODOS" was held in Kyiv. Experts from SNRIU, SE NNEGC "Energoatom", State Emergency Service of Ukraine, Ukrainian Hydrometeorological Center, State Enterprise "State Scientific and Technical Center for Nuclear and Radiation Safety", Khmelnytskyi NPP, Rivne NPP, Zaporizhzhia NPP were invited to participate in the training.

On October 11, 2013, testing was carried out on the RODOS software system, which was already installed at the IEC of the SNRIU. The testing was performed with participation of technical experts of the Karlsruhe Institute of Technology (KIT). The testing addressed, inter alia, issues of connection of the RODOS to the ASRM system and the system of operational weather forecasting for the Rivne NPP. At the Rivne NPP, RODOS uses global meteorological data covering the entire globe and predicts the movement of air masses in case of radiological accident, "dirty" bombs and other nuclear emergency scenario. Due to the cooperation with the Ukrainian Center for Environmental and Water Projects, which at one time developed the hydrological model of the river Stir for the RODOS system, and reprogrammed the RODOS system into the JAVA programming language (this version is currently used by European and Asian users), Rivne NPP installed software which allows to independently calculate the weather forecast for almost any territory of the Earth. The calculations are based on input from the US National Oceanic and Atmospheric Administration.

Today, RODOS system is operated by SNRIU's IEC, UHMC, State Emergency Service of Ukraine, Khmelnytskyi NPP, Rivne NPP, Zaporizhzhia NPP, South Ukraine NPP and State Agency of Ukraine on Exclusion Zone Management.

Since 2017 all Ukrainian JRodos users are supported by numerical weather prediction provided by Ukrainian Hydrometeorological Center (UHMC) and The Institute of Mathematical Machines and Systems Problems of the Ukraine National Academy of Science (IMMSP NASU). SNRIU's IEC has access to 96-hour NetCDF files WRF result and DMI-files covering the whole territory of Ukraine in real time (Fig. 6-7). Since 2019, more precise NWP are available separately for southern and northern parts of Ukraine.

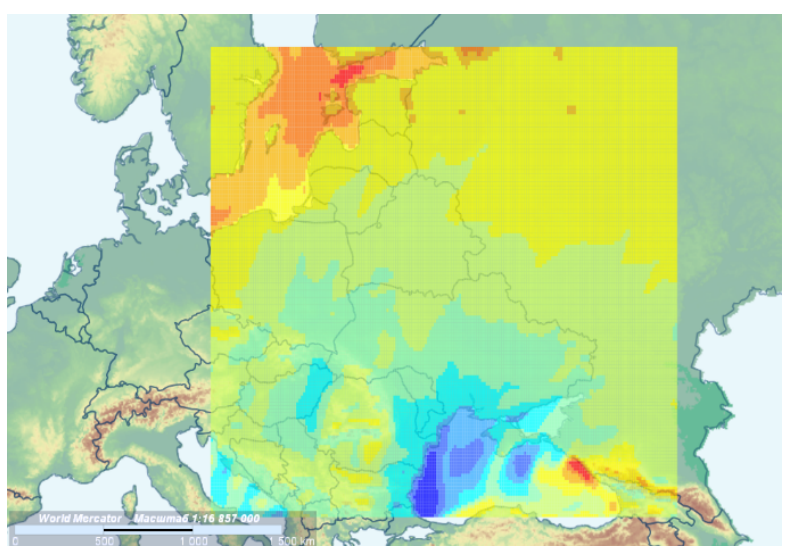

Fig. 6. NetCDF file - the whole territory of Ukraine and neighboring countries: duration of prognosis $-96 \mathrm{hrs,} \mathrm{step} \mathrm{of}$ updating $-6 \mathrm{hrs}$, spatial resolution $-0.15^{\circ}$.

JRodos-DataSupplier as an application to JRODOS system is installed in SNRIU's IEC for an automatic receipt of fresh numerical weather predictions for all the territory of Ukraine, parts of adjacent countries and for some territories around Ukrainian NPPs and Chornobyl Exclusion Zone. SSTC NRS experts have an access to sftp-server with numerical weather predictions data. Some additional weather information or extended numerical weather data can be required from Ukrainian Hydro-meteorological Center (UHMC). 


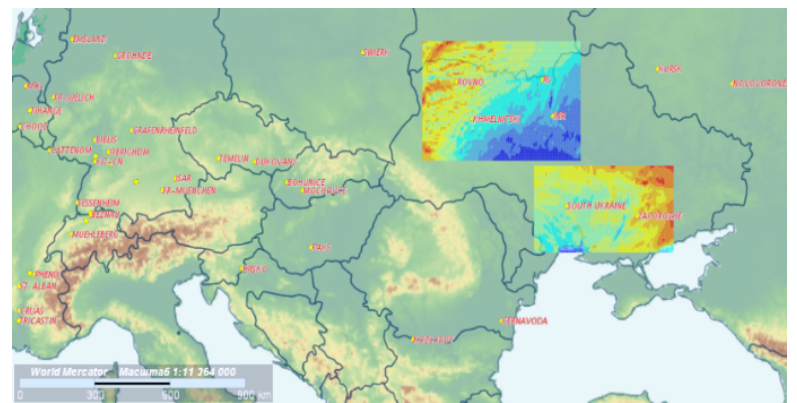

Fig. 7. NetCDF files covered Rivne NPP, Khmelnytskyi NPP, Chornobyl NPP and South Ukraine NPP, Zaporizhzia NPP: duration of prognosis $-96 \mathrm{hrs}$, step of updating $-6 \mathrm{hrs}$, spatial resolution $-0.05^{\circ}$.

HIRLAM files for MATCH model has the spatial limitation as for NetCDF files.

The system includes a number of atmospheric models that make it possible to simulate the motion of a radioactive cloud and atmospheric diffusion at different scales relative to the source term (Table 2). In [2], it was determined that the total amount of activity released during accidents involving the spill of liquid radioactive media is insignificant compared to severe accidents at nuclear power plants and leads to significant contamination of nearby areas in the path of radioactive cloud propagation. In the Table 2 shows the models of atmospheric transport by priority in order to solve the problem of estimating the radiation impact on the population for events with the spill of radioactive liquids.

Atmospheric dispersion modelling provides a lot of requirements be taken into ac-count in source term modeling for event associated with LRM. E.g., local scale model chains of DSS JRODOS allow to use several ways to fill in input parameters window. Most of them are used to bind to the initial activity (the number fission products) of the NPP reactor core. However, for cases where source term is undetermined by de-fault user library, such as wildfire in the contaminated forest, unintentional melting sources of ionizing radiation, emissions of pharmaceuticals and etc., it is possible to enter initial parameters at some number of time intervals (e.g., in the versions of DSS JRODOS 2017, 2019 - up to 128 time steps).
It is important to notice in most cases territory affected due to LRM spills are cordoned in near range scale. So scaling effects related to it (e.g. building wake effect shown in Fig. 8) should be considered in atmospheric dispersion modelling.

Moreover, selected time step of source term should be harmonized with both spatial resolution of modelling and time resolution of numerical weather data. Given the resolution of numerical meteorological data for the model RIMPUFF, a minimum results time step that correlates with local sensitivity JRODOS atmospheric dispersion models and meteorological pre-processor is 10 minutes. Such step allows to provide an accurate calculation in near and middle range up to 21 hours. In the case of input of stationary meteorological fields (manually) time step of the input data the source term needs additional adjustments in accordance with the minimal time step of meteorological data.

Practice of sensitivity analysis of such primary ones atmospheric propagation results as the integral radionuclide concentration in the ground layer to the general JRODOS initial data package in [21, 22], shows that the main problem in modelling is uncertainty in the source term. Such data include power, chronological parameters, speed, temperature, geometric height, radionuclide composition and physic-chemical forms of emission over time. For import source data from the outside or export to a file, the JRODOS system uses xmlformats.

\subsection{Uncertainties issue}

The practice of sensitivity analysis of such primary results of atmospheric propagation as integral concentration of radionuclide in the surface layer of air to the general package of initial data of JRODOS system shows that the main problem in modeling is uncertainty in initial data on source term. Such data include power, chronological parameters, velocity, temperature, geometric height, radionuclide composition and physicochemical forms of emission over time. To import source data from outside or export to a file, the RODOS system uses XML-formats.

Table 2. JRODOS atmospheric dispersion models.

\begin{tabular}{|c|c|c|c|c|c|c|}
\hline № & Name & Type & $\begin{array}{c}\text { Calculation } \\
\text { distance, } \mathbf{k m}\end{array}$ & \begin{tabular}{|c|} 
Resolution in \\
the results tree \\
(minimal), $M$ \\
\end{tabular} & $\begin{array}{l}\text { Meteorological } \\
\text { data format }\end{array}$ & Remark \\
\hline 1 & $\begin{array}{l}\text { RIMPUFF (RIsø Mesoscale } \\
\text { PUFF model) }\end{array}$ & $\begin{array}{l}\text { mesoscale } \\
\text { Lagrangian } \\
\text { puff model }\end{array}$ & $<800$ & $50 \times 50$ & $\begin{array}{l}\text { user-defined / } \\
\text { NWP data } \\
\text { NetCDF }\end{array}$ & $\begin{array}{c}\text { takes into account the initial } \\
\text { parameters of the atmospheric } \\
\text { dispersion; marked by stable } \\
\text { calculation }\end{array}$ \\
\hline 2 & $\begin{array}{c}\text { LASAT (LAgrange } \\
\text { Simulation of Aerosol } \\
\text { Transport) } \\
\end{array}$ & $\begin{array}{c}\text { Lagrangian } \\
\text { particle model }\end{array}$ & $<800$ & $50 \times 50$ & $\begin{array}{l}\text { user-defined / } \\
\text { NWP data } \\
\text { NetCDF } \\
\end{array}$ & $\begin{array}{l}\text { approved methodic approach } \\
\text { of doses assessment is used }\end{array}$ \\
\hline 3 & $\begin{array}{l}\text { DIPCOT (DIsPersion over } \\
\text { COmplex Terrain) }\end{array}$ & $\begin{array}{c}\text { Lagrangian } \\
\text { particle model }\end{array}$ & $<800$ & $50 \times 50$ & $\begin{array}{l}\text { user-defined / } \\
\text { NWP data } \\
\text { NetCDF }\end{array}$ & $\begin{array}{c}\text { takes into account the } \\
\text { complex terrain, however, } \\
\text { does not take into account the } \\
\text { initial parameters of } \\
\text { atmospheric dispersion } \\
\end{array}$ \\
\hline 4 & $\begin{array}{c}\text { MATCH } \\
\text { (Mesoscale Atmospheric } \\
\text { Transport and Chemistry) }\end{array}$ & $\begin{array}{l}\text { Eulerian } \\
\text { mesoscale } \\
\text { model }\end{array}$ & not limited & $\begin{array}{c}\sim 38000 \mathrm{x} \\
52000\end{array}$ & $\begin{array}{c}\text { binary format } \\
\text { GRIB (HIRLAM) }\end{array}$ & used for transboubdary tasks \\
\hline
\end{tabular}




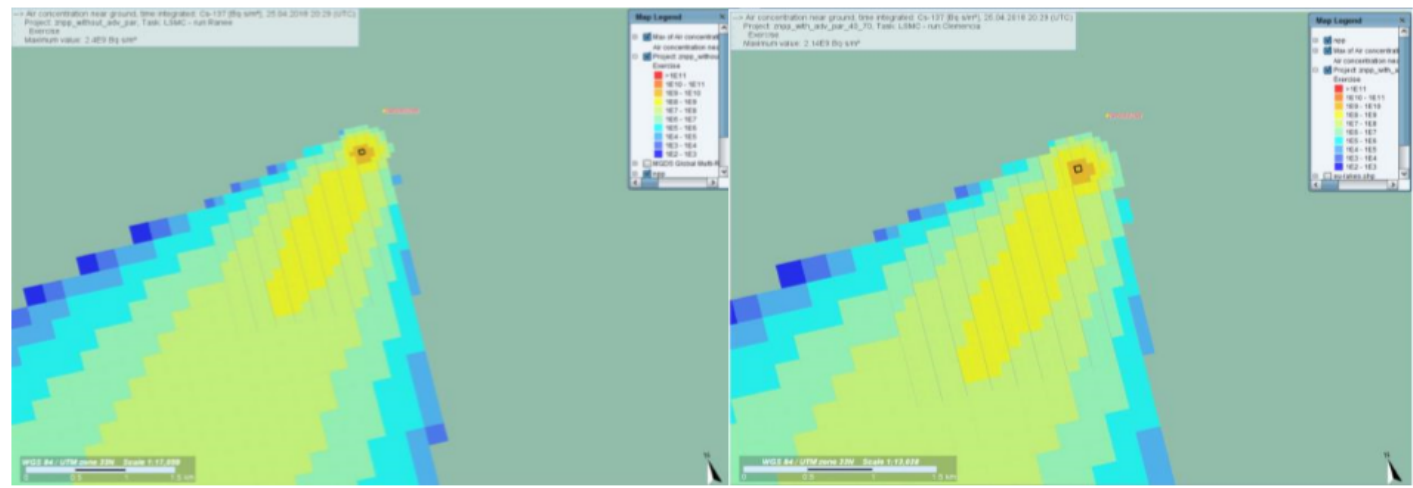

do not consider

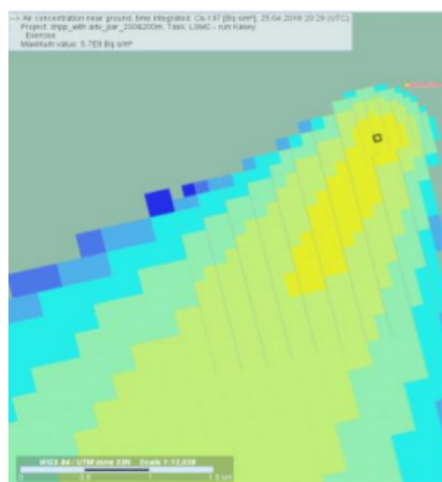

$b \times h_{b}=200 \times 200 \mathrm{~m}$ $b \times h_{b}=40 \times 70 \mathrm{~m}(\sim \mathrm{ZNPP}$ containment $)$

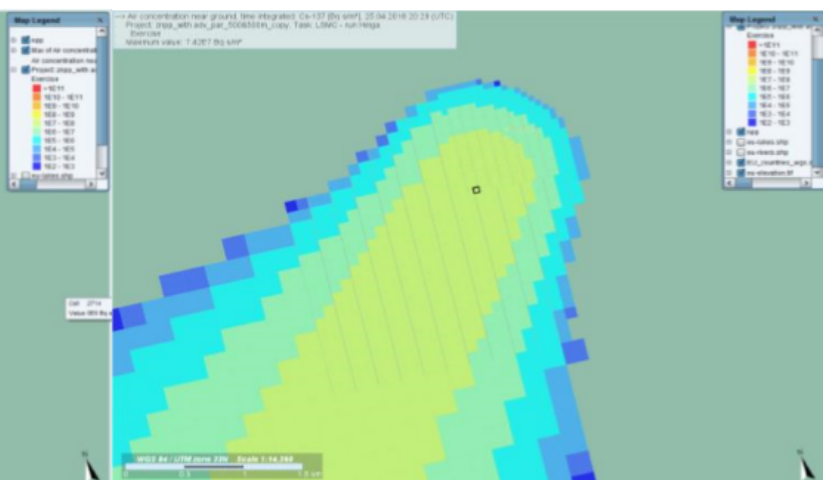

$b \times h_{b}=500 \times 500 \mathrm{~m}$

Fig. 8. NetCDF files covered Rivne NPP, Khmelnytskyi NPP, Chornobyl NPP and South Ukraine NPP, Zaporizhzia NPP: duration of prognosis $-96 \mathrm{hrs}$, step of updating $-6 \mathrm{hrs}$, spatial resolution $-0.05^{\circ}$.

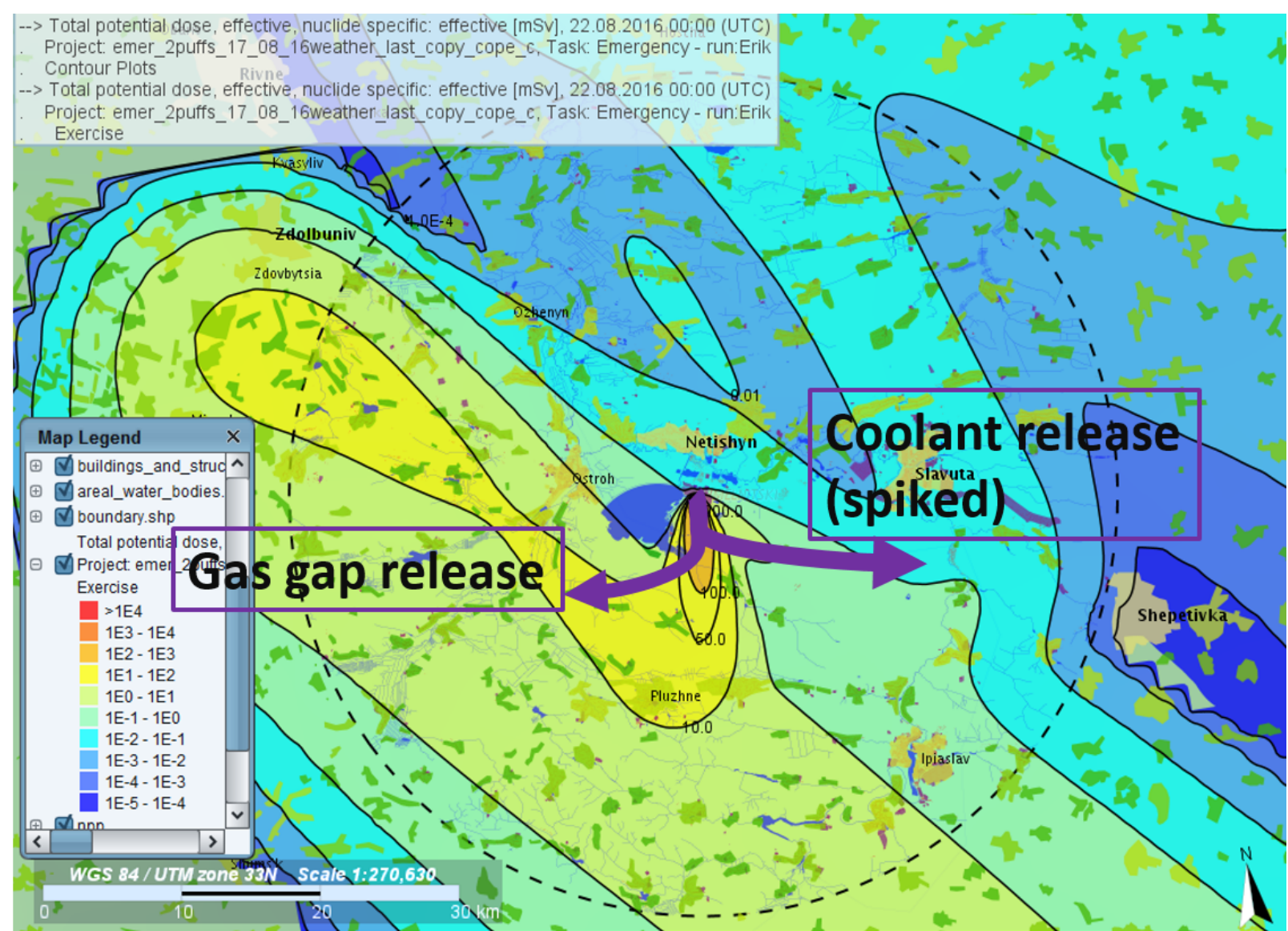

Fig. 9. Effective dose patterns from coolant and gas gap puffs (45-min difference between 2 release stages), mSv. 
The main task of modeling the emission source is to obtain a set of arrays of output parameters depending on the time variable using separate analytical and / or numerical means. However, a preliminary analysis of existing industry and industry-wide computer tools [2, 3] showed that modern modeling tools in this direction have a number of significant shortcomings that do not allow it to be used for quantification of emission sources in spills of liquid radioactive.

In frame of FASTNET project experience of more than 20 countries was analyzed. The main output of the project is an investigation in the area of qualitative characteristic of source term - resolution in time. Taking into account spatial and temporal resolution of numerical weather predictions used in Europe countries, FASTNET group recommend the use of 15-min intervals in source term.

Fig. 9 shows a case of unstable meteorological conditions within $30-\mathrm{km}$ surveillance zone of Khmelnytskyi NPP in summer 2016. This is an experience of SSTC NRS JRODOS calculation on NWPdata of July 11,2016 (1-hr, $0.15^{\circ}$ resolution). Source term was modelled for reactor core accident according to with consequent phenomenological steps coolant (spiked) release, gas gap release, and start of early in-vessel phase.

Practice of regular calculations demonstrates significant uncertainties in conjunction «source term NWP-data». Under unstable meteorological condition with complex patterns of integrated concentrations, using of more than 15-min. source term intervals can lead to crusual impact on radiological consequences results.

JRODOS users can operate pre-estimated source terms data. Source term library filling can be specified by requirements to source term files taking into account meteorology data resolution. Uncertainties of the source term on the prediction of atmospheric dispersion of released radioactivity involve both the amounts of radionuclides released and the temporal evolution of the release.

In AVESOME project [23], a methodology is developed which can handle both a few-member sourceterm ensemble and a large ensemble spanning all possible releases. The AVESOME methodology will work well with the Rapid Source Term Prediction (RASTEP) system, which provides a set of possible source terms with associated probabilities based on pre-calculated source terms. The methods, which are being developed in AVESOME, allows for efficient real-time calculations by making use of scaling properties in the equations governing the release and the atmospheric dispersion of radionuclides. Accordingly, the computer-resource demanding calculations should be carried out at the highperformance computing (HPC) facilities available e.g. at national meteorological services, whereas less demanding post-processing should be carried out at the computer hosting the DSS.

A protocol is suggested for interactive communication between the DSS and the HPC facility enabling the requests from the DSS user for long-range atmospheric dispersion model calculations. It is based on an existing operational protocol extended with the capability of simultaneous handling of a number of source-term descriptions, including a full source-term ensemble.

\subsection{Data exchange}

IRIX is a technical standard developed by the IAEA in cooperation with experts from Member States and the European Commission (EC). The standard is designed to enable the development of interoperable systems and solutions for exchanging emergency information and data between organizations at both national and international level during a nuclear or radiological incident or emergency. A principal concept in the IRIX Format is the IRIX report. Any information exchanged in the IRIX Format must be packaged as the IRIX report according to [24-26].

The IRIX report represents a message containing emergency related information and data, and/or requests for such information or data, sent from one organization to one or more other organizations. The IRIX report encompasses information such as basic information about the event (date and time of event, location, etc.), information about the status of the nuclear facility or radiation source involved, information about any releases of radioactive material to the environment, information on protective actions taken or planned to protect the public, and radiological monitoring data. The report covers information that is of immediate use to authorities for taking decisions on protective actions for the public, but also more detailed information and data that can be used for improving the assessment of the emergency situation and the subsequent decision making. The IRIX report structure supports the key categories of information to be exchanged internationally under the terms of the Convention on Early Notification of a Nuclear Accident. The use of the IRIX Format is, however, not limited to this application.

IRIX is an open format based on the Extensible Markup Language (XML), which makes it both machineand human-readable. It should be used to exchange radiological information between IAEA and RANET teams, or between any other two (or more) assisting parties, during a nuclear or radiological emergency. The IAEA has developed the IRIX format as the recommended standard to exchange information among emergency response organizations at national and international levels during a nuclear or radiological emergency. The standard covers the data content, the data format (XML), and the system interface specification. Data can include status information about a nuclear installation, information about any radioactive releases to the environment, information on protective actions taken or planned by affected countries, and environmental radiation monitoring data. Regarding to [26-28], the system interface specification (or web-service specification) enables organizations to interconnect their emergency information systems to automate their information exchange in an emergency. 


\section{Conclusions}

In the paper general context of radioactive liquids events in modelling area is presented. For the first time source term model for radioactive liquids spills taking into account technological premises and adjacent environmental has been proposed and developed. This model, unlike other models, takes into account the parameters of the radioactive liquid composition and the design conditions of their storage.

Possible ways of software integration of the developed mathematical model into atmospheric dispersion modelling and dose projection toolkit, taking into account the requirements of the adjacent radiological impact assessment tool and the specificity of liquid radioactive accident spill, is proposed. It solve the problem of complex radiological estimation for events including LRM. The developed model can be applied as useful tool of source term preparation in the case of LRM spill in advance as a well as in real time with a reasonable degree of conservatism. It allows to provide an adequate assessment of the radiological consequences for the set of initial conditions of accidents with spills of LRM in areas with forced ventilation.

IRIX format has been considered as an effective data exchange tool to perform the initial data or radiological consequences results in modelling area.

\section{References}

1. M. Dowdall, et al., Nordic Nuclear Accident Consequence. Analysis (NORCON): Final Report. NKS-353 (Roskilde, Denmark, 2015).

2. Y. Kyrylenko, I. Kameneva, O. Popov, A. Iatsyshyn, V. Artemchuk, V. Kovach, Source Term Modelling for Event with Liquid Radioactive Materials Spill, in Studies in Systems, Decision and Control, vol. 298, ed. by V. Babak, V. Isaienko, A. Zaporozhets (Springer, Cham, 2020), pp. 261-279. doi:10.1007/978-3-030-48583-2_17

3. Y. Kyrylenko, et al., Actual Issues on Radiological Assessment for Events with Liquid Radioactive Materials Spills. J. Health Pollut. (2021 in press)

4. R.L. Bangart, et al., Calculation of releases of radioactive materials in gaseous and liquid effluents from boiling water reactors (BWR-GALE Code) (NUREG--0016(Rev1)) (United States, 1978)

5. T. Chandrasekaran, J.Y. Lee, C.A. Willis, NUREG0016, Calculation of Releases of Radioactive Materials in Gaseous and Liquid Effluents from Boiling Water Reactors (U.S. Nuclear Regulatory Commission, Washington, 1985)

6. Radioactive Source Term for Normal Operation of Light Water Reactors, ANSI/ANS-18.1-1999

7. Radioactive Source Term for Normal Operation of Light Water Reactors, ANSI/ANS-18.1-2016 American National Standard (American Nuclear Society, 2016)
8. T. Poos, E. Varju, Determination of evaporation rate at free water surface, in 8th International Symposium on Exploitation of Renewable Energy Sources, pp. 66-71 (2016)

9. B.Ya. Zilberman, D.V. Ryabkov, E.A. Puzikov, E.V. Andreeva, N.E. Mishina, Influence of Pressure (Temperature) on the Nitric Acid Distribution between the Liquid and Vapor in the Course of Evaporation of Nitric Acid Radioactive Waste. Radiochemistry 3(58), 237-242 (2016)

10. M. Orvos, V. Szabo, T. Poos, Rate of Evaporation from the Free Surface of a Heated Liquid, J. Appl. Mech. Tech. Phys. 6(57), 1108-1117 (2016)

11. V. Lukashov, S. Romanko, S. Timofeev, A. Protsenko, Rate of Components Evaporation from Sulfuric Acid Solution During Its Concentrating in Air Flow. Chemistry \& Chemical Technology, 3(11), 344-348 (2017)

12. I. Ievdin, D. Trybushnyi, M. Zheleznyak, W. Raskob, An off-site emergency management system for nuclear accidents. Report. (Karlsruhe Institute of Technology, Karlsruhe, 2017)

13. G. Caminada, S. French, K. Politis, et al., Uncertainty in RODOS. Report RODOS(B)-RP(94)-05. (Karlsruhe Institute of Technology, Karlsruhe, 2000)

14. Realtime Online Decision Support System for nuclear emergency management (2015), https://resy5.iket.kit.edu/RODOS/. Accessed 27 Dec 2020

15. Materials on environmental impact assessment of the proposed activity on the operation of a nuclear facility, a complex of nuclear materials intended for radiochemical reprocessing of spent nuclear fuel (Federal State Unitary Enterprise "Production Association "Mayak", Ozersk, 2012)

16. A. Nesterenko, Fundamentals of thermodynamic calculations ventilation and air conditioning (Vysshaia Shkola, Moscow, 1971)

17. A. Nesterenko, Experimental study of heat and mass transfer during evaporation of the liquid with a free surface. Material science. Technical Physics 4(24) (1954)

18. V. Isachenko, V. Osipova, A. Sukomel, Heat transfer (Energiya, Moscow, 1975)

19. O. Volkov, Designing of industrial building ventilation (Vyscha Shkola, Kharkov, 1989)

20. S. Rivkin, A. Aleksandrov, Thermodynamic properties of water and steam. Directory (Energiya, Moscow, 1984)

21. ANSYS FLUENT 12.0 User's Guide. ANSYS, Inc. is certified to ISO 9001:2008 (2009), p. 2070

22. C. Greenshields, OpenFOAM User Guide version 6. The OpenFOAM Foundation (2018), p. 237.

23. Hawk Ridge Systems, SolidWorks Flow Simulation, https://hawkridgesys.com/solidworks. Accessed 27 Dec 2020 
24. Sandia National Laboratories, Sandia, https://www.sandia.gov. Accessed 27 Dec 2020

25. W. Raskob, C. Landman, D. Trybushnyi, Functions of decision support systems (JRodos as an example): overview and new features and products. Radioprotection 51(HS1), S9-S11 (2016)

26. HotSpot Health Physics Codes Version 3.0 User's Guide (National Atmospheric Release Advisory Center, LNLL, 2014), p. 198.

27. RASCAL 4.3 User's Guide (Ramsdell Environmental Consulting, LLC, 2013), p. 125

28. WinMACCS, a MACCS2 Interface for Calculating Health and Economic Consequences from Accidental Release of Radioactive Materials into the Atmosphere MACCS User's Guide (U.S. Nuclear Regulatory Commission, 2007), p. 233

29. I.A. Savushkin, E.I. Ravkova, O.B. Gourko, A.V. Ulanovskij, Construction of a set of typical WWER1000 severe accident source terms for training applications of RODOS, RODOS internal report, RODOS(WG7)-TN(98)-01 (1998).

30. L. Sági, P. Vértes, P.P. Szabo, L. Koblinger, Construction of a set of typical VVER440 design base accident source terms for training applications of RODOS, RODOS internal report RODOS(WG7)TN(97)-02 (1997).

31. J.H. Sørensen, et al., Added Value of uncertainty Estimates of Source term and Meteorology (AVESOME) (Nordic Nuclear Safety Research, 2018)

32. International Atomic Energy Agency, https://iec.iaea.org/usie/Exercise/Restricted/Message s/Genf.aspx. Accessed 27 Dec 2020

33. Council Decision of 14 December 1987 on Community arrangements for the early exchange of information in the event of a radiological emergency, 87/600/Euratom (Euratom, 1987)

34. Operations Manual for Incident and Emergency Communication. EPR-IEComm (IAEA, Vienna, 2019)

35. International Radiological Information Exchange (IRIX) Format. Reference Description IRIX Version 1.0. EPR-IEComm (IAEA, Vienna, 2019)

36. S. Mukhopadhyay, F. Baciu, G. Saluja, J. Segarra, F. Albinet, Application of International Radiological Information Exchange (IRIX) standards for radiation monitoring data reporting, in Proc. SPIE 10763, Radiation Detectors in Medicine, Industry, and National Security XIX, 1076308. doi:10.1117/12.23093802018.

37. Y. Balashevska, Y. Kyrylenko, O. Pecherytsia, I. Shevchenko, V. Bogorad, Harmonization of Methodological Approaches and Real Time Radiological Consequence Forecasting Tools. Nucl. $\begin{array}{llll}\text { Radiat. } & \text { Saf. 2(86), 20-26 (2020). }\end{array}$ doi:10.32918/nrs.2020.2(86).03 